\title{
QUANTIFICAÇÃO DE DEPÓSITOS E DETERMINAÇÃO DE ÁREA FOLIAR PARA TIRIRICA
}

Wellington Hipólito dos Santos ${ }^{1 *}$, Rodolfo Gonçalves Pereira ${ }^{1}$, Thiago Barbosa Gonçalves

Silva ${ }^{1}$, Acácio Aparecido Anunciação ${ }^{1}$, Valdinei dos Santos Oliveira ${ }^{1}$, Gustavo Rabelo Botrel Miranda ${ }^{2}$

1 Tecnólogo em Cafeicultura do Instituto Federal do Sul de Minas - Campus Muzambinho. Muzambinho/MG. *E-mail do autor correspondente: wellingtonhipolitodossantos@gmail.com

2 Professor EBTT do Instituto Federal do Sul de Minas - Campus Muzambinho. Area de atuação: Mecanização e Fitossanidade. Muzambinho/MG. E-mail: gustavo.miranda @ muz.ifsuldeminas.edu.br

RESUMO: O trabalho teve como objetivo propor um fator de correlação para estimar a área foliar de tiririca e verificar a ponta hidráulica que proporciona maior volume de depósitos nestas folhas. Para determinação da área foliar o delineamento experimental foi inteiramente casualizado (DIC), considerando-se 10 folhas como repetições, uma folha por parcela e utilizando-se dois métodos para determinar a correlação. Os tratamentos foram: Data Geosis e xerox. Não houve diferença significativa para os métodos de extração da área foliar, e, por isso, concluiu-se que o fator de correlação de 0,815 adéqua bem às folhas de tiririca. Em seguida foi desenvolvido um experimento em cafeeiro (Rubi MG-1192), espaçamento 3,7m x 1,0m em blocos ao acaso (DBC) para verificar a ponta hidráulica que proporciona maior volume de depósitos de pulverização com quatro tratamentos distribuídos em cinco blocos. A área das parcelas foi de $5 \mathrm{~m} \times 1,00 \mathrm{~m}$ e coletou-se cinco folhas de tiririca para serem lavadas e medidas posteriormente. A solução marcadora era composta pelo corante azul brilhante (FD\&C $\left.\mathrm{n}^{\circ} 1\right)$ a $0,15 \%(\mathrm{p} / \mathrm{v})$ e os tipos de pontas de pulverização, foram: leque duplo, leque comum, indução de ar e cônico vazio utilizando um pulverizador costal pressurizado $\left(\mathrm{CO}_{2}\right)$ com barra de 2 bicos espaçados em $50 \mathrm{~cm}$ e altura de $40 \mathrm{~cm}$. A solução extraída das amostras com corante foi lida em um espectrofotômetro a $630 \mathrm{~nm}$, onde determinou o volume depositado nas folhas em $\mu \mathrm{L} \mathrm{cm}^{-2}$. Conclui-se que a ponta duplo leque proporcionou maior quantidade de depósitos em folhas de tiririca.

Palavras-chave: Cyperus rotundus. Quantificação de depósitos. Tecnologia de aplicação. Plantas daninhas.

\section{DETERMINACION OF LEAF AREA AND QUANTIFICATION OF DEPOSITS ON LEAVES OF NUTSEDGE}

\begin{abstract}
The study was to verify the hydraulic tip that provides greater volume of deposits as well as propose a correction factor to estimate the leaf area of nutsedge. An experiment was conducted in IFSULDEMINAS - Campus Muzambinho in coffee plantation (Rubi MG-1192), spacing 3,7 m x 1,0 m. For determination of the leaf area was completely randomized experimental design, considering repetitions as 10 sheets, one sheet
\end{abstract}

Cultura Agronômica, Ilha Solteira, v.27, n.1, p.1-11, 2018 
per plot and using two methods to determine the correlation. The treatments were: Date Geosis and xerox. To check the hydraulic tip that provides greater volume of deposits was used a randomized complete block design for spray nozzles with four treatments over five blocks. The area of the plot was $5 \mathrm{~m} \times 1.00 \mathrm{~m}$ was collected 5 sheets of nutsedge and measures to be washed later. The solution was made by marker brilliant blue dye (FD \& $\mathrm{C}$ No. 1) $0.15 \%(\mathrm{w} / \mathrm{v}$ ) and the types of nozzles were: double range, common range, air induction hollow cone and using a knapsack sprayer pressurized $\left(\mathrm{CO}_{2}\right)$ with two bar nozzles spaced $50 \mathrm{~cm}$ and height $40 \mathrm{~cm}$. The solution samples extracted dye was read in a spectrophotometer at $630 \mathrm{~nm}$, which determined the amount deposited in the leaves $\mu \mathrm{L} \mathrm{cm}^{-}$ ${ }^{2}$. It is concluded that the tip double fan provided greater amount of deposits on leaves of nutsedge. There was no significant difference for the extraction methods of leaf area. It was found that the correlation factor of 0.815 fits well to the leaves of nutsedge.

Key words: Cyperus rotundus. Quantification of deposits. Application technology. Weed.

\section{INTRODUÇÃO}

A tiririca (Cyperus rotundus) é considerada como a mais importante planta daninha no mundo, devido a sua ampla distribuição, capacidade de competição e agressividade, bem como à dificuldade de controle e erradicação (DURIGAN et al., 2005).

A taxa de produção de tubérculos, sob boas condições edafoclimáticas, chega a ser de um a cada dois dias, e a densidade encontrada nos canaviais pode atingir 3.000 tubérculos. $\mathrm{m}^{-2}$, com produção de até 2.000 manifestações epígeas.m ${ }^{-2}$, as quais, após uma capina, crescem de um a três centímetros por dia; proporcionando assim, a maior a densidade da comunidade infestante e, portanto, mais intensa será a interferência da tiririca sobre a cultura (DURIGAN et al., 2005).

Devido à dificuldade de eliminação da tiririca torna-se imprescindível o uso correto da tecnologia de aplicação para que ocorra um controle satisfatório deste tipo de planta invasora.

Os componentes fundamentais de qualquer sistema de pulverização são os bicos. Também se enfatiza a importância do conhecimento das características do bico, pois além da formação de gotas, o bico é responsável na pulverização por outras duas funções fundamentais, como controlar a saída do líquido na quantidade desejada por unidade de tempo e espalhar as gotas formadas dentro de uma área delimitada (PERECIN et al., 1999) de forma a colocar o defensivo bem distribuído e em concentrações ideais no alvo químico, que neste caso é a planta daninha.

Para avaliação de depósitos em uma planta daninha associa-se às suas pequenas dimensões; portanto, as plântulas são expostas por um tempo extremamente curto (da ordem de $0,1 \mathrm{~s}$ ) ao jato de aplicação, o que, somado a fatores como oscilações e altura da barra, 
vento, tamanho da gota, estádio de desenvolvimento e área foliar, implica grande variabilidade dos depósitos unitários obtidos (SOUZA et al., 2007).

Por isso, o presente trabalho teve como objetivo verificar dentre as pontas de pulverização se existe diferença de volume de calda depositado em folhas de tiririca, bem como propor um fator de correlação para estimar a área foliar de plantas de tiririca em estudos de pulverização.

\section{MATERIAL E MÉTODOS}

\section{Experimento 1: Determinação do coeficiente de correlação para a área foliar de tiririca}

O experimento foi desenvolvido no Instituto Federal de Educação, Ciência e Tecnologia Sul de Minas Gerais - Câmpus Muzambinho/MG, em lavoura cafeeira de cultivar Rubi (MG-1192), lavoura adulta com espaçamento de 3,70m x 1,00m. Onde foram coletadas folhas de tiririca nas entrelinhas do cafeeiro.

Mediu-se a largura e o comprimento da folha a fim de formar um retângulo e determinar o fator de correlação.

Para determinação da área foliar e do coeficiente de correlação, foi utilizado o delineamento experimental inteiramente casualizado (DIC), considerando-se dez folhas como repetições, uma folha por parcela. Os dois métodos utilizados foram o método de pesagem de folhas para inferência de área foliar com xerox (GONDIM et al., 2009), e o calculado pelo software DATA GEOSIS.

\section{XEROX}

Para determinar a área foliar da tiririca coletou-se do limbo foliar um retângulo maior possível que tem seus lados medidos com régua para definir sua área, comprimento $\mathrm{x}$ largura (Ar). Tirou-se então xerox da folha para encontrar a massa seca deste retângulo (MSr) e a massa seca da folha recortada do retângulo (MSf) em que as áreas das folhas (AFf) foram retirados por regra de três simples, conforme Gondim et al. (2009), pela seguinte equação:

$$
\mathrm{AFf}=(\mathrm{MSf} \times \mathrm{Ar}) / \mathrm{MSr}
$$

Enfim, calculou-se o fator de correlação pela divisão da área foliar (Af) pela área do retângulo (Ar).

$$
\mathbf{F c}=\mathbf{A F f} / \mathrm{Ar}
$$

\section{DATA GEOSIS}

Para calcular a área foliar (AF) com o software topográfico Data Geosis Office versão: 7.5.1.0 (03/02/2011) foi criado um desenho a partir das imagens escaneadas em formato JPEG das folhas de tiririca (Cyperus rotundus), obtendo-se a área do desenho (AD) 
de cada uma das folhas de tiririca e a área do retângulo (AR) formado pelas dimensões da folha da tiririca (comprimento x largura).

Depois de encontrados os valores referentes às áreas dos desenhos das folhas e dos retângulos, esses valores eram transferidos para planilhas eletrônicas, software Microsoft Office Excel 2007, nas quais o fator de correlação foliar era obtido de acordo com a seguinte fórmula:

Onde:

$$
\mathbf{F c}=\mathbf{A D} / \mathbf{A R}
$$

$\mathrm{Fc}=$ Fator de correlação foliar;

$\mathrm{AD}=$ Área do desenho foliar;

$\mathrm{AR}=$ Área do retângulo.

\section{Experimento 2: Deposição de calda em folhas de tiririca}

O experimento foi desenvolvido no Instituto Federal de Educação Ciência e Tecnologia Sul de Minas Gerais - Campus Muzambinho/MG, em lavoura cafeeira de cultivar Rubi (MG-1192), lavoura adulta com espaçamento de 3,70m x 1,00m.

O delineamento utilizado foi em blocos ao acaso (DBC) com cinco repetições constituído de quatro tratamentos definidos por diferentes tipos de pontas hidráulicas de pulverização, sendo elas: ponta leque duplo (modelo TJ-60 11002 VS); ponta leque comum (modelo ADI 11002); ponta com indução de ar (modelo 11002); e ponta cônico vazio (modelo J-4), todos realizados com o auxílio de um pulverizador costal pressurizado $\left(\mathrm{CO}_{2}\right)$, barra com duas pontas de pulverização espaçadas $0,50 \mathrm{~m}$ e a $0,40 \mathrm{~m}$ de altura do alvo, calibrado para a vazão de $200 \mathrm{~L} \mathrm{ha}^{-1}$, com pressão de $241,32 \mathrm{kpa}$ (35PSI).

As parcelas foram constituídas de $5 \mathrm{~m}$ de comprimento por 3,70m de largura (entrelinhas de cafeeiros) sendo que a largura útil para a aplicação da calda foi de $1 \mathrm{~m}$. A pulverização foi feita no dia 23/03/2012, no período da tarde com pulverizador costal pressurizado $\left(\mathrm{CO}_{2}\right)$.

Para avaliar quantitativamente os depósitos decorrentes das pulverizações com as diferentes pontas de pulverização hidráulica foi preparada uma solução marcadora composta pelo corante azul brilhante (FD\&C no 1) a $0,15 \%$ (p/v) (PALLADINI, 2000). Utilizou-se essa solução marcadora para a avaliação quantitativa do volume de calda depositado nas folhas de tiririca.

Os dados meteorológicos (temperatura, umidade relativa do ar e velocidade do vento) durante a aplicação da calda de pulverização foram registrados por um termohigrômetro (Modelo HT-3003) e anemômetro (Modelo AM-4201), ambos da marca Lutron, posicionados a dois metros de altura da superfície do solo conforme adotado por Scudeler et al. (2004) no dia 24/03/12.

Após a aplicação da solução marcadora foram coletadas 5 folhas de tiririca de cada parcela utilizando luva cirúrgica e pinça para inseri-los em sacos plásticos identificados a 
fim de não ocorrer perda dos corantes no ato da coleta dos mesmos, e posteriormente leválos até o Laboratório de Bromatologia e Água do IFSULDEMINAS - Câmpus Muzambinho.

Segundo o método de Palladini (2000) a cada amostra adicionou-se $50 \mathrm{~mL}$ de água destilada, mantendo-a sob agitação por 30 segundos para a remoção do traçador. A solução resultante foi colocada em recipientes de vidros e mantida sob refrigeração $\left(8 \pm 3^{\circ} \mathrm{C}\right)$. Após este procedimento, os depósitos foram quantificados por um espectrofotômetro marca Femto 700s, pela leitura da absorbância no comprimento de onda de $630 \mathrm{~nm}$.

Obteve-se a área foliar multiplicando as dimensões foliares por 0,815 , conforme a formula abaixo:

Onde:

$$
\mathrm{AF}=\mathrm{C} * \mathbf{L} * \mathbf{0 , 8 1 5}
$$

$\mathrm{AF}=$ Área foliar em centímetro quadrado $\left(\mathrm{cm}^{2}\right)$;

$\mathrm{C}=$ Comprimento da folha em centímetro $(\mathrm{cm})$;

$\mathrm{L}=$ Maior largura da folha $(\mathrm{cm})$;

$0,815=$ Constante (fator de correlação)

A solução de água e corante provida da extração das amostras de tiririca foram lidas em espectrofotômetro com o comprimento de onda de 630 nanômetros, onde determinou-se o volume depositado nas folhas através da seguinte equação:

$$
\mathbf{C i} * \mathbf{V i}=\mathbf{C f} * \mathbf{V f}
$$

Onde:

$\mathrm{Ci}=$ Concentração inicial da calda $(1500$ ppm);

$\mathrm{Vi}=$ Volume inicial a ser calculado;

$\mathrm{Cf}=$ Concentração final que corresponde à concentração encontrada na leitura do espectrofotômetro;

$\mathrm{Vf}=$ Volume utilizado para lavar as folhas.

Após a determinação de volume depositado, calculou-se a deposição em microlitros $(\mu \mathrm{L})$ de calda por centímetro quadrado $\left(\mathrm{cm}^{2}\right)$ de superfície foliar.

Os valores de absorbância lidos pelo espectrofotômetro proporcionaram a sua transformação em ppm (mg. $\left.\mathrm{L}^{-1}\right)$ de acordo com o coeficiente angular da curva-padrão estabelecida pelas diluições das amostras (1/25, 1/50, 1/100, 1/200, 1/500, 1/1000, 1/2000, 1/5000, 1/10000) de cada calda de pulverização coletada no campo.

Verificou-se a equação $\left(\mathrm{y}=0,0718 \mathrm{e}^{0,7564 \mathrm{x}}\right)$, obtendo o valor da concentração em ppm do corante azul brilhante a partir da substituição do valor $\mathrm{x}$ da equação pela leitura da absorbância da amostra aferida no espectrofotômetro.

Os valores obtidos referentes ao acúmulo de depósito em folhas e os valores do fator de correlação para as folhas de tiririca foram submetidos à análise de variância pelo teste $\mathrm{F}$ e

Cultura Agronômica, Ilha Solteira, v.27, n.1, p.1-11, 2018 
as médias comparadas pelo teste de Tukey ao nível de 5\% de probabilidade realizada pelo software de análises estatísticas SISVAR 4.3 (FERREIRA, 2011).

\section{RESULTADOS E DISCUSSÃO}

\section{Experimento 1: Determinação do coeficiente de correlação para folhas de tiririca.}

Os resultados da análise estatística mostraram que não houve diferença significativa para métodos utilizados para determinar o fator de correlação foliar (Tabela 1).

Tabela 1. Valores médios do fator de correlação para folhas de tiririca (Cyperus rotundus) obtidos pelos métodos adotados para determinação da área foliar. IF Sul de Minas Campus Muzambinho. 2012.

\begin{tabular}{cc}
\hline Métodos & Volume/área foliar $\left(\mu \mathrm{L} . \mathrm{cm}^{-2}\right)$ \\
\hline Data Geosis & $0,8037 \mathrm{a}$ \\
Xérox & $0,8300 \mathrm{a}$ \\
\hline CV $(\%)$ & 10,47 \\
F & 0,5587
\end{tabular}

Resultados expresso por teste $\mathrm{F}$ e médias. As médias seguidas pela mesma letra minúscula na coluna não diferem entre si pelo teste de Tukey a 5\% de significância.

De acordo com os resultados obtidos pelos métodos aplicados (Tabela 1), o valor de 0,815 adéqua bem as folhas de tiririca e devido a isso foi utilizado nos cálculos da área foliar para inferência de depósitos de calda com diferentes modelos de pontas de pulverização.

Pinto et al. (2008) afirmaram que para cada espécie devem ser determinados modelos, os quais podem ser utilizados em estudos com a mesma espécie, desde que os parâmetros dimensionais de comprimento e largura amostrados estejam dentro do intervalo para o qual os modelos foram estabelecidos. Entretanto, quando cultivares de uma espécie têm formato foliar diferente é necessário estabelecer novos modelos de predição.

Silva et al. (2008) propôs um método de cálculo de área foliar para café utilizando uma fórmula simples, onde utiliza a multiplicação do comprimento e largura com um fator de correlação igual a 0,66666 (2/3). No entanto folhas de café são elípticas e folhas de tiririca são planas e sulcadas (KISSMANN, 1997). Desta forma, tornou-se necessário adequar o fator de correlação para esta mesma fórmula.

A determinação da área foliar (AF) das plantas é de interesse em diferentes setores da pesquisa agronômica, porém é de fundamental importância que as técnicas de estimativa de área foliar sejam simples, rápidas e, principalmente, não destrutivas (GONDIM et al., 2009).

Cultura Agronômica, Ilha Solteira, v.27, n.1, p.1-11, 2018 


\section{Experimento 2: Deposição do corante em folhas de tiririca}

Para a obtenção da concentração do corante na amostra em mg. $\mathrm{L}^{-1}$, foi desenvolvida uma curva de calibração, efetuando-se a leitura no espetrofotômetro, de concentrações conhecidas do corante.

A quantificação do corante marcador possibilitou o estabelecimento da seguinte equação $\left(y=0,0718 \mathrm{e}^{0,7564 \mathrm{x}}\right)$ com coeficiente de determinação $\mathrm{R}^{2}=0,9989$ para a calda de pulverização durante a aplicação, onde:

$\mathrm{X}=$ leitura da densidade óptica (absorbância);

$\mathrm{Y}=$ concentração em ppm, pois a concentração de corante foi a mesma em todos os tratamentos. (Figura 1).

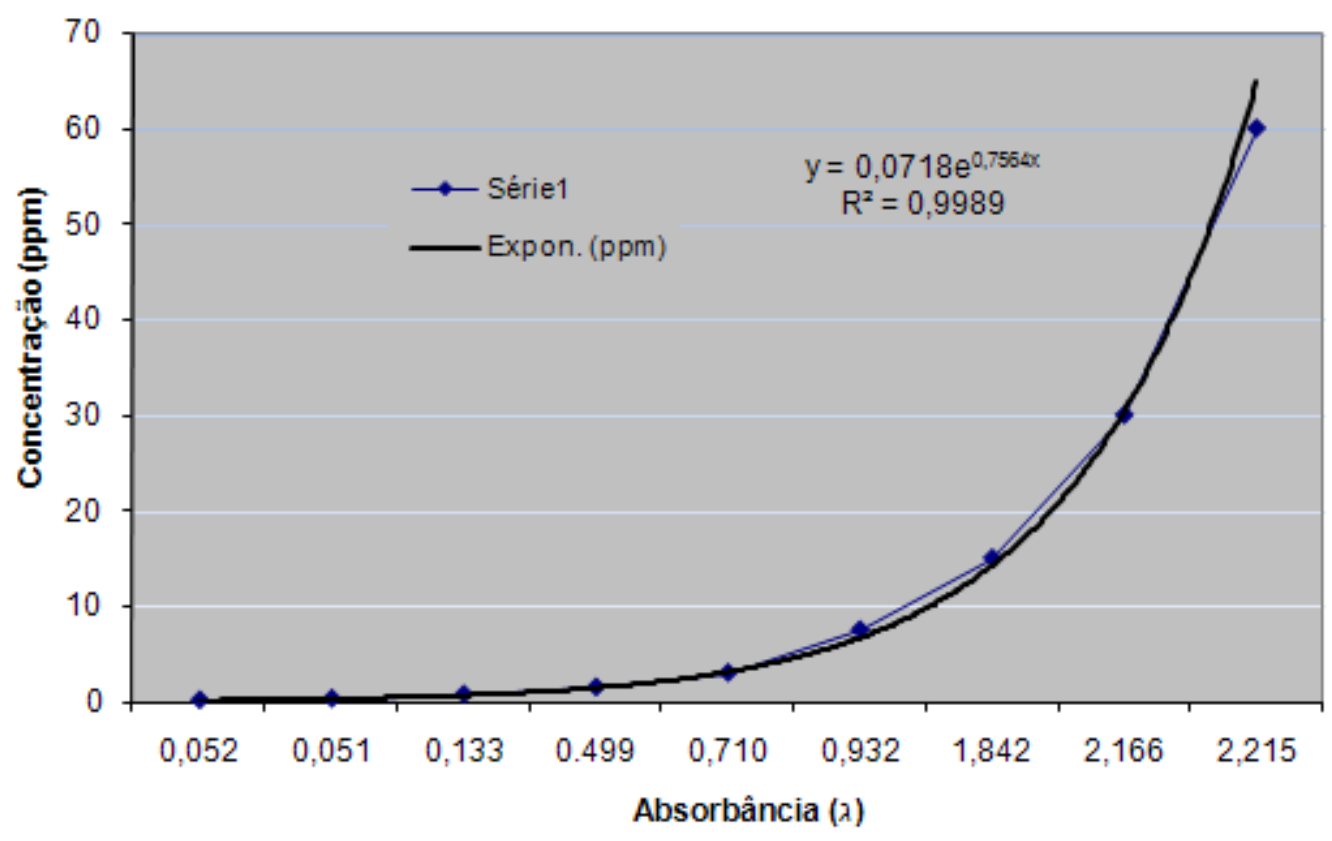

Figura 1. Curva de leitura de absorbância para inferir a concentração das amostras de calda. IF Sul de Minas - Campus Muzambinho.

Os valores médios de acúmulo de depósitos de pulverização retidos em folhas de tiririca proporcionados por diferentes modelos de pontas de pulverização hidráulica estão apresentados na Tabela 2.

Observa-se na Tabela 2 que a ponta de jato cônico vazio proporcionou menor quantidade de calda retido em folhas de tiririca dentre todos os modelos de pontas de pulverização testados, a ponta leque duplo proporcionou maior acúmulo de depósitos retidos em área foliar de tiririca. As outras pontas de pulverização, do tipo leque e do tipo indução de ar, apresentaram resultados significativamente intermediários para deposição de volume de calda acumulado em folhas de tiririca. 
Tabela 2. Valores médios de depósitos $\left(\mu \mathrm{L} . \mathrm{cm}^{-2}\right)$ após pulverização com diferentes modelos de pontas de pulverização em folhas de tiririca. IF Sul de Minas - Campus Muzambinho.

\begin{tabular}{cc}
\hline Modelo da ponta de pulverização & Volume/área foliar $\left(\mu \mathrm{L} . \mathrm{cm}^{-2}\right)$ \\
\hline Leque duplo & $0,09060 \mathrm{a}$ \\
Leque comum & $0,08300 \mathrm{ab}$ \\
Indução de ar & $0,08180 \mathrm{ab}$ \\
Cônico vazio & $0,06800 \mathrm{~b}$ \\
Média geral & 0,08085 \\
\hline CV $(\%)$ & 13,21 \\
F & 0,0376
\end{tabular}

Resultados expressos por teste $\mathrm{F}$ e médias. As médias seguidas pela mesma letra minúscula na coluna não diferem entre si pelo teste de Tukey a 5\% de significância.

A pressão de trabalho utilizada, em torno de $214 \mathrm{kPa}$, equivalente a $35 \mathrm{PSI}$, que é o suficiente para o trabalho com todas as pontas estudadas, com exceção à ponta do tipo cone vazio que suporta uma condição de pressão maior.

As pontas de pulverização possuem características diferenciadas, sendo que podem proporcionar resultados diferentes em uma pulverização, em função de vários valores. É correto dizer que, para cada situação que necessitar de aplicação de defensivo agrícola, existirá uma ponta mais adequada para que a calda pulverizada atinja o alvo desejado (BOSCHINI, 2006).

Segundo Costa et al. (2008), o sucesso da dessecação consiste em uma cobertura mínima, uniforme e de elevada qualidade e está diretamente relacionado com o diâmetro das gotas, que também estabelece o seu comportamento quanto à distância do alvo (deriva), à penetração na folhagem, à perda por evaporação e, conseqüentemente, à taxa de recuperação, além da arquitetura da planta, regulagem do equipamento, velocidade de trabalho e escolha ideal de pontas que juntos influenciarão na chegada das gotas no alvo.

O tamanho de gotas e a velocidade do vento interferem na trajetória e deposição das gotas no alvo. Por isso, de acordo com as condições ambientais, é necessário conhecer o espectro de gotas pulverizadas, de forma a ajustar o seu tamanho, e, ao mesmo tempo, garantir eficácia biológica e segurança ambiental. Vale considerar que gotas menores que $100 \mu \mathrm{m}$ são facilmente levadas pelo vento, e são mais sensíveis aos efeitos climáticos (CUNHA et al., 2003).

Estas pontas, formadoras de gotas pequenas, que neste trabalho foram o duplo leque, o leque comum e o cônico vazio, também são capazes de fornecer gotas que proporcionam uma maior penetração foliar e maior superfície de cobertura podendo, desta forma, ser utilizada com mais segurança os produtos herbicidas que agem por contato.

As pontas de jato cone vazio (TX Teejet) foram largamente utilizadas na aplicação de fungicidas devido a sua característica de produzir gotas menores em pressões mais elevadas e assim apresentar uma boa penetração nas folhagens (BONINI, 2003). 
No entanto, as pontas de jato cone vazio utilizadas neste trabalho formam um ângulo de abertura do jato igual a $80^{\circ}$, diferente de todas as outras pontas utilizadas que formam ângulos de abertura do jato igual a $110^{\circ}$. Este fato aliado a distância entre pontas na barra pode ter influenciado negativamente no acúmulo de deposição de calda para esta ponta de pulverização.

A ponta com indução de ar, que, apesar de não ter fornecido uma condição capaz de reter tanto líquido quanto a ponta modelo duplo leque, pode ser utilizada para aplicação de herbicidas sistêmicos sem tanto risco de proporcionar deriva, porém sem a mesma capacidade de cobertura, pois este modelo de ponta forma diâmetro de gotas maiores.

Entre os componentes do equipamento de aplicação, as pontas de pulverização estão entre as partes mais importantes do pulverizador na determinação do diâmetro das gotas da pulverização. Se selecionadas corretamente, definindo modelo, tamanho e pressão de trabalho, garantem a segurança ao meio ambiente e ao operador e a eficiência da aplicação (COSTA, 2007; PEREIRA et al., 2016). O uso de pontas que produzem gotas grossas e com deriva reduzida - como é o caso das pontas com indução de ar - pode resultar em condições de trabalho mais seguras para os trabalhadores expostos.

Costa et al. (2008) observaram que a ponta AI 11002 VS (200 L ha-1) foi a ponta que obteve a menor deposição de gotas, porém proporcionou maior uniformidade de distribuição dentre os modelos testados, na cultura da Brachiaria brizantha.

Em experimento visando avaliar a deposição e a deriva de calda fungicida aplicada em feijoeiro, em função dos bicos de pulverização (jato plano e jato cônico vazio) e dos volumes de aplicação de 125 e $250 \mathrm{~L} \mathrm{ha}^{-1}$, Cunha et al. (2005) concluíram que os bicos de jato plano e de jato cônico vazio proporcionaram cobertura semelhante da folhagem do feijoeiro, tanto na posição superior quanto na inferior do dossel. Concluíram também que as gotas formadas nas aplicações com bicos de jato cônico vazio estão sujeitas à deriva que as produzidas com bicos de jato plano, especialmente quando se emprega baixo volume de aplicação.

\section{CONCLUSÃO}

Dentre as pontas de pulverização, a de jato leque duplo, proporcionou maior deposição da calda nas folhas de tiririca. Não ocorreu diferença entre os métodos de extração da área foliar, sendo o coeficiente de correlação proposto de 0,815 para as folhas de tiririca.

\section{REFERÊNCIAS BIBLIOGRÁFICAS}

BONINI, J. V. Tecnologia de aplicação de fungicidas na cultura da soja. 2003. 67 f. Dissertação (Mestrado em Agronomia) - Universidade Federal de Santa Maria, Santa Maria, 2003.

Cultura Agronômica, Ilha Solteira, v.27, n.1, p.1-11, 2018 
BOSCHINI, L. Avaliação de deposição da calda de pulverização em função do tipo de ponta e do volume de aplicação, na cultura da soja. 2006. 32 f. Dissertação (Mestrado em Agronomia) - Universidade Estadual do Oeste do Paraná, Marechal Cândido Rondon, 2006.

COSTA, G. M. Segurança do trabalhador em aplicações de herbicidas com pulverizadores de barra em cana-de-açúcar. 2007. 62 f. Dissertação (Mestre em Produção Vegetal) - Faculdade de Ciências Agrárias e Veterinárias, Universidade Estadual Paulista, Jaboticabal, 2007.

COSTA, N. V.; RODRIGUES, A. C. P.; MARTINS, D.; CARDOSO, L. A.; SILVA, J. L. C. Efeito de pontas de pulverização na deposição e na dessecação em plantas de Brachiaria brizantha. Planta Daninha, Viçosa, v. 26, n. 4, p.923-933, 2008.

CUNHA, J. P. A. R.; TEXEIRA, M. M.; VIEIRA, R. F.; FERNANDES, H. C. Deposição e deriva de calda. Revista Brasileira Engenharia Agricola Ambiental, Campina Grande, v. 9, n. 1, p.127-138, 2005.

CUNHA, J. P. A. R.; TEIXEIRA, M. M.; COURY, J. R.; FERREIRA, L. R. Avaliação de estratégias para redução da deriva de agrotóxicos em pulverizações hidráulicas. Planta daninha, Viçosa, v. 21, n. 2, p.325-332, 2003.

DURIGAN, J. C.; CORREIA, N. M.; TIMOSSI, P. C. Estádios de desenvolvimento e vias de contato e absorção dos herbicidas na inviabilização de tubérculos de Cyperus rotundus. Planta daninha, Viçosa, v. 23, n. 4, p.621-626, 2005.

FERREIRA, D. F. Sisvar: a computer statistical analysis system. Ciência e Agrotecnologia. Lavras, v. 35, n. 6, p.1039-1042, 2011.

GONDIM, T. M. S.; SILVA, F. F. S.; FERNANDES, P. D.; BELTRÃO, N. E. M.; SILVA FILHO, J. L. Teor relativo de água e métodos para determinação de área foliar em algodão colorido Gossypum hirsutum Cultivar BRS 200 marrom. In: CONGRESSO BRASILEIRO DO ALGODÃO, 7, 2009, Foz do Iguaçu. Anais... 2009. p. 941-951. Disponível em <http://www.cnpa.embrapa.br/produtos/algodao/publicacoes/anais_cba7.pdf>. Acesso em: 12 ago. 2017.

KISSMANN, K. G. Plantas infestantes e nocivas: plantas inferiores monocotiledôneas. 2.ed. São Paulo: Editora BASF, 1997. 608 p.

PALLADINI, L. A. Metodologia para avaliação da deposição em pulverizações. 2000. 111 f. Tese (Doutorado em Proteção de Plantas) - Faculdade de Ciências Agronômicas, Universidade Estadual Paulista, Botucatu, 2000.

PERECIN, D.; PERESSIN, V. A.; MATUO, T.; BRAZ, B. A.; PIO, L. C. Avaliação do desempenho de bicos para aplicação de herbicidas. Planta Daninha, Viçosa, v. 17, n. 1, p.83-94, 1999.

PEREIRA, R. G.; SILVA, T. B. G.; ANUNCIAÇÃO, A. A.; SANTOS, W. H.; MIRANDA, G. R. B.; ALVES, A. D.; SARTORI, R. H. Quantificação de depósitos em folhas de 
trapoeraba com diferentes tipos de pontas de pulverização. Revista Agrogeoambiental, Pouso Alegre, v. 8, n. 1, p.47-56, 2016.

PINTO, A. C. R.; GRAZIANO, T. T.; BARBOSA, J. C.; LASMAR, F. B. Modelos para estimativa da área foliar de Cúrcuma alismatifolia e Cúrcuma zedoaria. Bragantia. Campinas, v. 67, n. 2, p.549-552, 2008.

SCUDEler, F.; RAETANO, C. G.; ARAUJO, D.; BAUER, F. C. Cobertura da pulverização e maturação de frutos do cafeeiro com ethephon em diferentes condições operacionais. Bragantia, Campinas, v. 63, n. 1, p.129-139, 2004.

SILVA, A. R.; LEITE, M. T.; FERREIRA, M. C. Estimativa da área foliar e capacidade de retenção de calda fitossanitária em cafeeiro. Bioscience Journal, Uberlândia, v. 24, n. 3, p.66-73, 2008.

SOUZA, R. T.; VELINI, E. D.; PALLADINI, L. A. Aspectos metodológicos para análise de depósitos de pulverização pela determinação dos depósitos pontuais. Planta Daninha, Viçosa, v. 25, n. 1, p.195-202, 2007. 